Revista do CESP, Belo Horizonte, v. 37, n. 58, p. 44-55, 2017

\title{
Figurações do pensamento-paisagem na recente poesia de Fernando Echevarría
}

\section{Thought-Landscape Figurations in the Recent Poetry of Fernando Echevarría}

\author{
Arturo Diaz \\ Centro de Estudos Filosófico-Humanísticos/Universidade Católica Portuguesa, \\ Braga / Portugal \\ arturodiaz@live.com.pt
}

Resumo: Este estudo funda-se no conceito de "pensamento-paisagem" de Michel Collot e exprime duas direções de sentido: primeiro, o processo genético deste pensamento que engendra paisagens abstratas; em segundo lugar, as paisagens mentais exprimem o espaço do pensamento figurativo. Descrevemos também os modos de génese deste novo campo do pensamento e as suas propriedades.

Palavras-chave: "pensamento-paisagem"; processo, génese, espaço do pensamento.

Abstract: This communication is based on the concept of "thoughtlandscape" of Michel Collot and expresses two directions of meaning: first, the genetic processes of this thought that unfolds in landscapes and landscapes that express the space of figurative thinking. Then the description of the engendering of this new field of thought and its properties.

Keywords: "thought-landscape"; process, genesis, space of thought.

Recebido em 30 de outubro de 2017

Aprovado em 9 de janeiro de 2018 


\section{Conceito de "pensamento-paisagem"}

Vamos focalizar a nossa abordagem numa obra poética recente, datada de 2013, intitulada Categorias e outras paisagens. Esta obra distribui-se em quatro seç̧ões, todas elas ligadas entre si e orientadas para a expressão dessa paisagem última da vida do poeta. O livro inicia com o poema "É o que vemos que nos reza dentro"; seguem-se as secções "Retiro", "Paisagem prévia", "Aguarela", "Paisagem evolutiva" e "Retrato".

$\mathrm{O}$ poeta continua fiel às matrizes do seu ofício, caracterizado por uma poética fenomenológica da revelação da luminosidade do ser que se exprime na génese do espaço do pensamento e nessa espiritualidade de sagração jubilosa do mundo.

Nesta obra, o seu intelecto agente e operativo absorve e submete a uma análise intelectual a multiplicidade do concreto, que fulgura nesse novo espaço mental construído, numa outra dimensão espácio-temporal, e que recebe o nome de lugar, campo e paisagem. A paisagem será uma espécie de campo transcendental do pensamento alto, povoado de signos virtuais, puras imagens e figurações do mundo. Neste sentido, o nosso conceito "pensamento-paisagem", inspirado em Michel Collot, exprime um duplo movimento que vai da abstração dos sinais sensíveis do mundo para o campo dos signos virtuais, que compõem e dão consistência à paisagem transcendental do pensamento. Como precisa Michel Collot: "Permite, ao mesmo tempo, sugerir que a paisagem provoca o pensar e que o pensamento se desdobra como paisagem." (COLLOT, 2013, p. 12)

Uma ascese ou linha evolutiva dianoética expansiva percorre esta obra, rumo ao engendramento dessas paisagens mentais, puras imagens que fulguram nesse pensamento abstrato e visual. As ditas categorias são os conceitos operativos do engendramento dessas paisagens que, morando dentro, se abrem ao horizonte sensível do mundo. Há momentos, porém, em que apenas persiste a evidência da imagem do mundo como uma epifania, revelação instantânea do ser pelas figuras e que se manifesta nessa reverberação aurática em torno dos entes concretos:

Porque é à volta do vulto que a paisagem se ilumina. (ECHEVARRÍA, 2013, p. 30) 


\section{O processo poético}

As janelas dão sempre para estarmos a ver por elas o que não se vê - o ponto onde o fenómeno é epifania de acto, a palpitar por trás no tempo só de ser. (ECHEVARRÍA, 1998)

O pensamento abre-se a paisagem.

Uma pura paisagem. (ECHEVARRÍA, 2013, p. 58)

Vamos descrever o processo de engendramento dessas paisagens do espírito, processo esse imanente que implica o exercício das faculdades da alma, concretamente a percepção da retina amante das coisas do mundo. A cada dia que passa, o poeta contrói e erige uma nova paisagem, embora a descrição desse processo de engendramento se repita com discreta variação de um elemento ou outro que se acrescenta. A Obra inacabada (2006) de Fernando Echevarría é de uma rigorosa e tensa coerência interna nos seus mecanismos estilísticos, temas e processos de engendramento do novo espaço mental. O poeta figura-se como um nómada imóvel, contemplativo, que caminha firme na fé, nesta Terra dos vivos. O que dá sentido à sua existência eminentemente contemplativa são esses conceitos operativos ou as ditas categorias e as paisagens do espírito que ele constrói e cria.

Deste modo, e no âmbito de uma despovoadora ascese de corte dos ruídos mundanos, o estudo analítico, árduo e paciente, o silêncio gerador e o vazio são condições da irrupção das inéditas paisagens mentais. Tudo isto é necessário para que a nova paisagem mental surja, uma paisagem do e no pensamento:

O espírito espera do silêncio que ele dê lugar ao vazio (ECHEVARRÍA, 2013, p. 482)

No termo do processo do ver, analisar e escrever no regime da imanência perceptiva, cessa essa mestria contida e rigorosa das visões escritas para dar lugar à manifestação da paisagem mental em si, composta de figuras e imagens, nesse campo ou lugar do pensamento abstrato, objectivo e impessoal: 
Por fim, recua a mestria.

Só aparece a paisagem

Transposta quase fixa

Mas de justiça da imagem. (ECHEVARRÍA, 2013, p. 266)

A descrição do processo torna-se mais explícita no poema "O sol de inverno empalidece". A sua fria luz grava-se primeiro na inteligência, passando pela retina amante, antes de se inscrever na palavra. E é no regime intersticial das passagens entre a intelectualização do fenómeno e a sua expressão verbal que se experimenta o efeito incorporal impassível como Acontecimento, a tal eficácia operativa que extrai do real a sua essência ou potencial virtual e a sua consequente actualização no plano da expressão:

Assim, aos poucos, sofre-se e se enreda

o labor da recíproca distância:

uma exaurindo do real a essência

e a outra, real, a realizá-la. (ECHEVARRÍA, 2013, p. 262)

É por isso que estas paisagens têm uma consistência virtual ou pregnância ontológica que resulta da coalescência ou movimento de reversibilidade entre o potencial virtual e o actual. Há, por conseguinte, um modo ligado de individuação singular intensivo nesta poesia que vai das multiplicidades virtuais sensíveis, passando pelo acto de percepção reconfigurador, e desaguando no acto de escrita e no processo de leitura.

As paisagens do espírito são construídas para serem habitadas como fenómeno eminentemente perceptivo em movimento rítmico de figuras e imagens. Elas exprimem o movimento do pensamento nele mesmo, de onde emanam as palavras fundadoras, aquelas que perduram, após a almejada transposição para o plano musical e pictural:

Frequentam-se as paisagens. Cada vez,

que entrando forem por elas

haverá somente ver

e ritmo de inteligência.

(...)

O que sobrevém

é a grande realeza

do real. Está de pé. 
Fundado. Mas na evidência

da palavra que se fez

no seio do que se pensa. (ECHEVARRÍA, 2013, p. 253)

Por isso, cada paisagem do espírito exprime a potência afectiva da alegria abrindo o horizonte do visível, o rio e as margens contempladas, serenamente. Em última instância, a paisagem mental resulta do cruzamento transversal e da sobreposição do vidente e do visível, mas também da sua inscrição rítmica em palavras transbordantes de júbilo, palavras essas captadas no fluxo do pensamento:

Mas também a vir dar à luz da mesa onde adequados ritmos a consignam, antes de entrar pela alegria imensa

Que toma conta da da nostalgia. (ECHEVARRÍA, 2013, p. 254)

\title{
3. Génese do espaço do pensamento
}

\author{
Paisagem era. Interior. O espaço, \\ ultrapassada qualquer categoria \\ ou lugar, ondeava. Pronto. E apto \\ ao advento maior. \\ (ECHEVARRÍA, 2013, p. 481)
}

Dito isto, já não é a expressão da derradeira paisagem singular que se afigura como protagonista desta Obra, nem sequer a figuração do tempo abstracto e metafísico. Para nós, a singularidade deste livro e desta poesia tem a ver com a génese do espaço do pensamento figurativo. $\mathrm{E}$ para isso vamos focalizar a nossa leitura num poema que mostra esses processos de engendramento da paisagem, mas, sobretudo, descreve a génese dessa nova topologia do pensamento.

Neste poema, que é também a expressão jubilosa, aproximada, do que será a última paisagem do poeta engendrada na Terra dos vivos, assistimos a uma tensão de sentido entre o concreto empírico e a sua figuração mental e virtual, no campo do pensamento abstrato. Não se trata de um mero jogo paradoxal de sentido nem sequer de uma mera disjunção exclusiva ou divergência de incompatibilidades. O poema, utilizando uma terminologia da ontologia deleuziana, exprime uma disjunção inclusa, 
que passa pela afirmação da coalescência entre o atual empírico e o potencial virtual, da transposição dos sinais do mundo-natura para o plano dos signos e da expressão.

Este é o poema da celebração exultante da cor da plumagem e do canto dos pássaros, transposta logo para o plano abstrato de uma pauta musical. Esse canto transparente marca um ritmo veloz de signos truncados, enquanto que a sua penetração na espessura do bosque inscreve uma lentidão própria de um adagio. É da intersecção e do cruzamento destes dois planos rítmicos que, no espaço mental do pensamento alto, resulta essa "glória abrupta" do mundo-natura ab intra, uma alegria inenarrável que brota de dentroe, ao mesmo tempo, a expressão do júbilo do processo da obra em construção, a tal Obra inacabada.

Esta Obra resisite aos ruídos da facticidade mundana para instaurar o espaço do silêncio, da escuta e do vazio criadores. Daí a acentuada desaceleração e lentidão transcendental que ela inscreve como prefiguração e condição de uma aceleração do pensamento intuitivo e figurativo. É assim que, pelo impulso do arroubo e do rapto, o poeta entra no campo de uma ontologia imanente do ser unívoco como processo e expressão. O canto dos pássaros que se inscreve na pauta musical é como o verso que, no poema, se exprime em truncados signos. Não obedecendo à linearidade da sintaxe lógica, abre-se à leitura plural e infinita:

Que glória abrupta. Que truncados signos.

Que tessitura a referir a festa

Da obra em acto. A surdir do limbo

desta lúcida paz de experiência

que os pássaros, estritos, vão abrindo

na leitura de pautas tão dissertas. (ECHEVARRÍA, 2013, p. 308)

A espera infinita é a paisagem, tudo é paisagem, o espaço e o tempo, nesse movimento de reversibilidade entre vidente/visível. Quase que somos tentados a subscrever a fórmula epistemológica do idealismo objectivo: esse est percipi. No entanto, creio que nesse insistente e tenso movimento de coalescência entre o potencial virtual e o actual empírico e no plano do ser como expressão da palavra proferida e fundadora de paisagens inéditas, a poética de Fernando Echevarría está mais próxima do empirismo transcendental de Gilles Deleuze (1997). Como acabámos de descrever, os seus processos de engendramento do espaço 
do pensamento figurativo são imanentes, abrindo, no entanto, as clareiras e as dobras da invisível transcendência.

Aí, nem sequer haverá a paisagem final, porque o desejo imanente deseja sempre mais além de si, num processo infinito de engendramento expressivo das singularidades visíveis. As páginas finais do livro não encenam essas fulgurantes paisagens derradeiras que o horizonte de expectativa do leitor almeja. Se o último poema fosse aexpressão da paisagem procurada, o poder de agenciamento do desejo expressivo de singularidades sensíveis ficaria limitado e virtualmente cessaria. Da compenetração da inteligência operativa, eminentemente perceptiva e auditiva, no mundo das multiplicidades sensíveis, surge esse movimento e ritmo ondulante no pensamento, na escrita, tensa, contida e rigorosa. Os signos abrem e indicam esse horizonte longínquo do visível. O desejo imanente exprime essa repetição e insistência da visão contemplativa escrita se manifestar como uma evidência, uma objectividade pura, liberta de profundezas egóicas e subjectividades psicológicas. A paisagem vê, tendo passado o limiar das categorias da representação e dos conceitos reflexivos de uma consciência doadora de sentido:

Pois o desejo

só se cumpre à medida que deseja

mais para além de si.

(...)

Aí, recolhe-se o conhecimento

a um repouso movente de certeza

que repõe a visão. E o visto a ver-nos

mais para além de toda a inteligência. (ECHEVARRÍA, 2013, p. 485)

A origem fecunda da evidência da paisagem videnteimplica essa nova topologia intensiva, um espaço interior aberto ao mundo. No horizonte perceptivo do mundo, há uma reversibilidade entre videntel visível e esse movimento entre o dentro e o fora engendra o plano de imanência da escrita-mundo, sem a mediação das categorias dicotómicas da representação. O intelecto operativo e agente abre o corpo ao mundo, apreende o mundo, através do intelecto expressivo que revela as entidades virtuais da paisagem. Por conseguinte, é um processo de revelação, ao modo de epifanias: 
E hão-de aparecer campos escritos.

(...)

E, de aí por diante, o aberto é

altura activa, paisagem indo

à procura do que há-de aparecer. (ECHEVARRÍA, 2013, p. 44)

A topologia ondulante e vibrante de que falamos, é um espaço genético de paisagens e, de certo modo, um plano de consistência perceptivo em construção, que, virtualmente, exprime a omnitudo da Terra. Efectivamente, cada paisagem, na sua singularidade irredutível, exprime a omnitudo espacial da terra, como se de uma mónada se tratasse. Cada paisagem do espírito é como que um departamento do mundo; sendo uma sua parte constitutiva, exprime a totalidade porque envolve uma perplicação de singularidades afetivas, percetivas e auditivas que se desdobra na sonoridade rítmica das linhas escritas:

A espera interior é uma paisagem
a abrir-se devagar a toda esta
que estamos vendo quase que a apagar-se,
aos poucos saturando-se de espera.
E a espera cresce veemente. Afaz-se
à plenitude espacial da terra,
agora a erguer-se aos píncaros. (ECHEVARRÍA, 2013, p. 469)

Podemos traçar um conjunto de problemas: quais as propriedades desse novo espaço do pensamento? E qual a textura desse campo de consistência? Como e quando é que a imanência dos processos de génese do espaço mentalabre o horizonte da transcendência?

Digamos que esse lugar, campo, espaço do pensamento-paisagem consiste efetivamente num novo espaço gerado no cerne do tempo. Esta poética instaura uma desaceleração do tempo cronológico para que o espaço se amplifique e dilate, nesse campo transcendental e impessoal do pensamento, construido a partir de uma radical despersonalização ou devir-imperceptível desta singularidade contemplativa e pensante que aqui tem um nome: Fernando Echevarría. Movimento de um pensamento imanente composto de figuras e imagens que, nesse regime da evidência e da intuição, prescinde das categorias reflexivas e da sua explicação numa linearidade lógico-sintáctica. A textura desta nova topologia é a paisagem interior, espaço puramente intensivo eondulante, onde se efectuam e encarnam as visões-acontecimentos: 
Chegado a ser ninguém. Abriu-se um campo

Que só à extensão se abria.

(...)

Paisagem era. Interior. O espaço,

ultrapassada qualquer categoria

ou lugar, ondeava. Pronto. E apto

ao advento maior. (ECHEVARRÍA, 2013, p. 481)

Além de ondulante, esta nova topologia do pensamento imanente vibra de uma "luz desconhecida/ que levamos implícita." (ECHEVARRÍA, 2013, p. 482). Tecido de silêncio e vazio absoluto, despojado do ritmo empírico, do pensamento e do pensado mesmo, é um puro plano de imanência apto a receber a efectuação e encarnação do acontecimento, e neste sentido, um infinito actual. Ainda no âmbito da monadologia leibniziana, cada paisagem do espírito exprime não só a omnitudo da Terra, como cada Visão, com todo o seu potencial cognitivo, exprime todas as visões anteriores e futuras:

\author{
Ao que advier será aberto \\ espaço novo. Luz. Sítio \\ adequado a só seu peso \\ referido ao infinito. (ECHEVARRÍA, 2013, p. 482)
}

Mas o que será, então, a paisagem nesta poética?

Vários poemas tentam responder a esta inquirição. Antes mesmo da sua fundação pela palavra, há a paisagem vista, a escrita e a lida, massobretudo a que foi captada pela retina amante, imanente, sem mediações categoriais, num momento de individuação singular intensiva, que extrai a essência do potencial virtual do atual empírico. Durante a visão, o estudo analítico é frio e mental. Só assim emerge a paisagem com brilho próprio, puramente objectiva e portadora de uma verdade. Esta verdade resulta de uma aliança entre a imanência dessa lavoura da luz interior e essa outra Luz de Deus que ilumina as paisagens do espírito que perduram:

Então a paisagem luz. Assenta.

E a palavra que a discrimina.

A funda na verdade. Na certeza

de, pronta, vir a lume cada dia. (ECHEVARRÍA, 2013, p. 475) 


\author{
Viagem? Sim. Bem se vê: \\ as paisagens que se deixam \\ são aquelas com que Deus \\ iluminou esta festa \\ de irmos firmes. (ECHEVARRÍA, 2013, p. 494)
}

\title{
4. Conclusão
}

Afinal, as paisagens mais pregnantes que exprimem essa concretude do concreto, a sua essência ou potencial virtual, são as paisagens do espírito, mentais e abstractas, que vão sendo construídas pelo intelecto operativo e no pensamento alto, nesse campo onde é possível "[...] ouvirmos/ a própira pulsação do pensamento." (ECHEVARRÍA, 2013, p. 488). É aí que as paisagens manifestam a sua evidência expressiva e consistem, porque duram infinitamento no pensamento figurativo da singularidade nómada, imóvel e contemplativa:

\author{
Aí, a paisagem vinga. Os pássaros \\ sobressaem, profundos e antigos, \\ como os nomes destrinçam os riachos \\ ou assombram a paração dos bichos. \\ Tudo é eterno. Também tudo páramo. \\ Em tudo se incutiu o paraíso. (ECHEVARRÍA, 2013, p. 444)
}

$\mathrm{Na}$ realidade, é o trabalho da língua escrita nas suas plurais componentes fónico-prosódicas, rítmicas, morfo-sintácticas e semânticopragmáticas que abre esse horizonte do novo espaço do pensamentopaisagem. Neste novo espaço, a língua ganha ímpeto para poder inscrever as Visões-acontecimentos no plano de expressão, através de um movimento de contra-efectuação das profundezas abissais do negativo. Tendo aí entrado com determinação impetuosa, gera-se o movimento autónomo da expressão do sentido e do contido visionarismo:

Largou-lhe velas para inchar o ritmo

e rigor para o voo visionário

se ajustar à certeza do sentido

e à renovação mental do pasmo.

A língua ruma. Fez o seu caminho

interior. (ECHEVARRÍA, 2013, p. 457) 
A leitura será, por conseguinte, o modo de actualição das multiplicidades virtuais perceptivas e auditivas, e uma operação de rasura da subjectividade psicológica. Como sabemos, a figura consiste numa transcendência sensitiva que enlaça o plano empírico com o transcendental e exprime uma ontologia da imanencias. A figura e a imagem são os elementos constitutivos da paisagem, cuja vocação é a abertura ao mundo, no modo musical e pictural:

Tudo passou a pintura.

A pintura a verbo abstracto.

E ambos passam na leitura

que se actualiza em ambos. (ECHEVARRÍA, 2013, p. 287)

\section{Referências}

COLLOT, Michel. Poética e filosofia da paisagem. Tradução de Ida Alves et al. Rio de Janeiro: Editora Oficina Raquel, 2013.

DELEUZE, Gilles, Différence et Répétition, Paris, PUF, 1997.

ECHEVARRÍA, Fernando. Geórgicas. Porto: Edições Afrontamento, 1998.

ECHEVARRÍA, Fernando. Obra inacabada. Prefácio de Maria João Reynaud. Porto: Edições Afrontamento, 2006.

ECHEVARRÍA, Fernando. Categorias e outras paisagens. Porto: Edições Afrontamento, 2013. 